\title{
Absorption of carbon dioxide by the absorbent composed of piperazine and 2-amino-2-methyl-1-propanol in PVDF membrane contactor
}

\author{
Su-Hsia Lin ${ }^{\mathrm{a}, *}$, Pen-Chi Chiang ${ }^{\mathrm{b}}$, Chun-Fan Hsieh ${ }^{\mathrm{c}}$, Meng-Hui $\mathrm{Li}^{\mathrm{c}}$, Kuo-Lun Tung ${ }^{\mathrm{c}, \mathrm{d}}$ \\ ${ }^{a}$ Department of Chemical and Material Engineering, Nanya Institute of Technology, Chung-Li 32091, Taiwan \\ ${ }^{\mathrm{b}}$ Graduate Institute of Environmental Engineering, National Taiwan University, Taipei 106, Taiwan \\ ${ }^{\mathrm{c}}$ Department of Chemical Engineering, Chung Yuan Christian University, Chung-Li 32023, Taiwan \\ ${ }^{\mathrm{d}} R \& D$ Center for Membrane Technology, Chung Yuan University, Chung-Li 32033, Taiwan
}

Received 3 October 2007; accepted 26 November 2007

\begin{abstract}
This paper tests the performance of microporous polyvinylidinefluoride (PVDF) hollow fiber in a gas absorption membrane process (GAM) using the aqueous solutions of piperazine (PZ) and 2-amino-2-methyl-1-propanol (AMP). Experiments were conducted at various gas flow rates, liquid flow rates and absorbent concentrations. Experimental results showed that wetting ratio was about $0.036 \%$ when used with the aqueous alkanolamine solutions, while that was $0.39 \%$ with aqueous piperazine solutions. The $\mathrm{CO}_{2}$ absorption rates increased with increasing both liquid and gas flow rates at $N_{\mathrm{Re}}<20$. The increase of the PZ concentration showed an increase of absorption rate of $\mathrm{CO}_{2}$. The $\mathrm{CO}_{2}$ absorption rate was much enhanced by the addition of PZ promoter. The resistance of membrane was predominated as using a low reactivity absorbent and can be neglected as using absorbent of AMP aqueous solution. The resistance of gasfilm diffusion was dominated as using the mixed absorbents of AMP and PZ. An increase of PZ concentration, the resistance of liquid-film diffusion decreased but resistance of gas-film increased. Overall, GAM systems were shown to be an effective technology for absorbing $\mathrm{CO}_{2}$ from simulated flue gas streams, but the viscosity and solvent-membrane relationship were critical factors that can significantly affect system performance.
\end{abstract}

(C) 2008 Taiwan Institute of Chemical Engineers. Published by Elsevier B.V. All rights reserved.

Keywords: Carbon dioxide absorption; Piperazine; 2-amino-2-methyl-1-propanol; PVDF hollow fiber; Membrane contactor; Wetting

\section{Introduction}

Carbon dioxide has been proven to be the largest contribution of greenhouse gases, increasing of the earth's surface temperature. And it is reported that half of the $\mathrm{CO}_{2}$ emission is produced by power plants using fossil fuels (Desideri and Paolucci, 1999). Therefore, the development of a separation process is highly needed to remove and to recover the $\mathrm{CO}_{2}$ from the places generating $\mathrm{CO}_{2}$ gas. In general, the bubble columns, packed towers, venturi scrubber, sieve trays can be used to remove the $\mathrm{CO}_{2}$. The commercial process widely known for $\mathrm{CO}_{2}$ separation is the packed column system, but new technology is required for this because of disadvantages of

\footnotetext{
* Corresponding author. Fax: +886 34652040 .

E-mail address: sslin@ nanya.edu.tw (S.-H. Lin).
}

the packed column system, such as flooding, channeling, largescale equipment, etc. Gas absorption membrane (GAM) process was considered as an alternative to recovery of $\mathrm{CO}_{2}$ from waste gas streams. Hollow fiber membrane contactor (HFMC) offers a much larger contact area per unit volume compared to tray and packed columns, which has the advantages of no flooding, entrainment, and foaming restrictions on operation flow rates (Gabelman and Hwang, 1999; Rangwala, 1996).

The mass transfer resistances of gas, membrane, and liquid phases limit the $\mathrm{CO}_{2}$ absorption rate in the membrane contactor module. Although the interfacial area of the membrane is greater than conventional absorbers, the increase of its additional membrane resistance can cause a decrease in the mass transfer capacity of the membrane ( $\mathrm{Li}$ and Chen, 2005). Therefore, to minimize the membrane resistance plays an important part in the gas absorption 


\begin{tabular}{|c|c|}
\hline \multicolumn{2}{|c|}{ Nomenclature } \\
\hline$a$ & gas-liquid contact area $\left(\mathrm{m}^{2} / \mathrm{m}^{3}\right)$ \\
\hline$d_{\mathrm{i}}, d_{\mathrm{o}}$ & $\begin{array}{l}\text { inside and out side diameter of the fiber, respec- } \\
\text { tively }(\mathrm{m})\end{array}$ \\
\hline$D_{\mathrm{e}}$ & average of diffusivity defined as Eq. (7) $\left(\mathrm{m}^{2} / \mathrm{s}\right)$ \\
\hline$D_{\mathrm{g}}$ & diffusivity of $\mathrm{CO}_{2}$ in gas phase $\left(\mathrm{m}^{2} / \mathrm{s}\right)$ \\
\hline$D_{\mathrm{k}}$ & Knudsen diffusivity of $\mathrm{CO}_{2}\left(\mathrm{~m}^{2} / \mathrm{s}\right)$ \\
\hline$D_{\mathrm{L}}$ & diffusivity of $\mathrm{RNH}_{2}$ in liquid phase $\left(\mathrm{m}^{2} / \mathrm{s}\right)$ \\
\hline E & enhancement factor \\
\hline$H_{\mathrm{e}}$ & Henry's law constant of $\mathrm{CO}_{2}\left(\mathrm{~m}^{3} \mathrm{kPa} / \mathrm{kmol}\right)$ \\
\hline$J_{\mathrm{CO}_{2}}$ & flux of $\mathrm{CO}_{2}\left(\mathrm{kmol} / \mathrm{m}^{2} \mathrm{~s}\right)$ \\
\hline$k_{\mathrm{g}}$ & $\begin{array}{l}\text { gas phase mass transfer coefficient } \\
\left(\mathrm{kmol} / \mathrm{s} \mathrm{m}^{2} \mathrm{kPa}\right)\end{array}$ \\
\hline$k_{\mathrm{L}}$ & liquid-film mass transfer coefficient $(\mathrm{m} / \mathrm{s})$ \\
\hline$k_{\mathrm{m}}$ & membrane mass transfer coefficient $(\mathrm{m} / \mathrm{s})$ \\
\hline$k_{\mathrm{OH}}^{*}$ & reaction rate of $\mathrm{CO}_{2}$ hydration \\
\hline$k_{\mathrm{ov}}$ & $\begin{array}{l}\text { overall pseudo first-order reaction rate constant } \\
(1 / \mathrm{s})\end{array}$ \\
\hline$K_{\mathrm{L}}$ & overall liquid phase mass transfer coefficient $(1 / \mathrm{s})$ \\
\hline$L$ & fiber length $(\mathrm{cm})$ \\
\hline$n$ & number of fibers \\
\hline$P$ & overall pressure $(\mathrm{kPa})$ \\
\hline$P_{\mathrm{BM}}$ & log-mean partial pressure of inert $(\mathrm{kPa})$ \\
\hline$P_{\mathrm{g}}, P_{\mathrm{i}}$ & $\begin{array}{l}P_{\mathrm{m}} \mathrm{CO}_{2} \text { partial pressures in the bulk gas phase, } \\
\text { membrane-liquid interface, and gas-membrane } \\
\text { interface, respectively }(\mathrm{kPa})\end{array}$ \\
\hline$P_{\mathrm{M}}$ & log-mean partial pressure of $\mathrm{CO}_{2}(\mathrm{kPa})$ \\
\hline$r_{\mathrm{ov}}$ & $\begin{array}{l}\text { overall pseudo first-order reaction rate }(\mathrm{kmol} / \\
\left.\mathrm{m}^{3} \mathrm{~s}\right)\end{array}$ \\
\hline$R$ & gas constant $(\mathrm{kJ} / \mathrm{mol} \mathrm{K})$ \\
\hline$R_{\mathrm{CO}_{2}}$ & absorption rate of reaction of $\mathrm{CO}_{2}\left(\mathrm{kmol} / \mathrm{m}^{3} \mathrm{~s}\right)$ \\
\hline$R_{\mathrm{M}}, R_{\mathrm{G}}$ & $\begin{array}{l}R_{\mathrm{L}} \text { were represented as the resistances of mem- } \\
\text { brane, gas-film and liquid-film diffusion }\end{array}$ \\
\hline$T$ & absolute temperature $(\mathrm{K})$ \\
\hline$v_{\mathrm{g}}$ & velocity of gas phase $(\mathrm{m} / \mathrm{s})$ \\
\hline$v_{\mathrm{L}}$ & velocity of liquid phase $(\mathrm{m} / \mathrm{s})$ \\
\hline$X$ & $\begin{array}{l}\text { average fractional depth of penetration of liquid } \\
\text { into pores }\end{array}$ \\
\hline Greek s & ymbols \\
\hline$\Delta_{\mathrm{m}}, \Delta$ & $\begin{array}{l}\Delta_{\mathrm{L}} \text { were represented as the fractional resistances } \\
\text { of membrane, gas-film and liquid-film diffusion } \\
\text { to overall resistances defied as Eq. (11). }\end{array}$ \\
\hline$\beta$ & penetration ratio of liquid \\
\hline$\varepsilon$ & porosity of membrane \\
\hline$\gamma_{\mathrm{H}}$ & hydraulic irradius (m) \\
\hline$\mu$ & viscosity of liquid ( $\mathrm{m} \mathrm{Pa} \mathrm{s}$ ) \\
\hline$\mu_{\mathrm{g}}$ & viscosity of gas (Pa s) \\
\hline$v_{\mathrm{L}}$ & velocity of liquid $(\mathrm{m} / \mathrm{s})$ \\
\hline$\rho$ & density of gas phase $\left(\mathrm{kg} / \mathrm{m}^{3}\right)$ \\
\hline$\tau$ & fiber tortuosity \\
\hline
\end{tabular}

process by using a polymeric membrane contactor. The success of this technology is highly dependent on the wetting relationship between the membrane and liquid solvent used in the system.
The alkanolamine group is mainly used as absorbent for removal of the $\mathrm{CO}_{2}$ due to its high reaction rate. A wide variety of alkanolamines has been studied in the literatures, such as monoethanolamine (MEA), $N$-methyldiethanolamine (MDEA), diglycolamine (DGA), di-2-propanolamine (DIPA), and 2-amino-2-methyl-1-propanol (AMP)(Li and Lie, 1994; Song et al., 1996; Versteeg and van Swaaij, 1988). Piperazine has a higher reaction than primary alkanolamine like MEA because of its cyclic and diamine nature, considered as a promoter for methyl diethanolamine (Bishnoi and Rochelle, 2000; Xu et al., 1992, 1998). The sterically hindered amines such as AMP also have higher cyclic capacities of $\mathrm{CO}_{2}$ than conventional primary and secondary amines such as MEA, diethanolamine (DEA), and diisopropanolamine (DIPA) and more appreciable rates of absorption (Satori and Savage, 1983).

However, the properties of these sterically hindered amines are unflavored mainly due to the instability of carbamate (Alper, 1990; Chakraborty et al., 1986; Saha et al., 1995). Recently, it has been shown that a solution of two or more amines improves the absorption rate and reduces the solvent regeneration energy (Chakravarty et al., 1985; Seo and Hong, 1996). Appl et al. (1982) reported that piperazine would be more effective than the conventional absorption accelerators. $\mathrm{Xu}$ et al. (1992) investigated the kinetics of $\mathrm{CO}_{2}$ absorption in activated MDEA solutions that contained piperazine as an activator. Xiao et al. (2000) investigated the kinetics of $\mathrm{CO}_{2}$ into aqueous solutions of AMP with the small addition of MEA. They suggested a hybrid reaction model, a first-order reaction for MEA, and a zwitterions mechanism for AMP to interpret the kinetic data. Here the aqueous mixtures solutions of piperazine and AMP were chosen as a novel absorbent in this study.

Although there are some literatures that investigated the $\mathrm{CO}_{2}$ absorption in hollow fiber. Yeon et al. (2003) have ever investigated the $\mathrm{CO}_{2}$ absorption in PVDF and PTFE hollow fiber membrane using single absorbent (MEA). Wang et al. (2004) studied the $\mathrm{CO}_{2}$ capture by three typical amines solutions (MDEA, AMP and DEA) in hollow fiber membrane contactors. Yeon et al. (2004) have ever studied the $\mathrm{CO}_{2}$ absorption rate using the mixed absorbent of $\mathrm{PZ}$ and TEA. However, the characteristics and efficiency of the mixed absorbents on membrane were not clear. In this study, we experimentally investigated the $\mathrm{CO}_{2}$ absorption rate in a PVDF membrane contactor using a mixture solution of PZ and AMP. The influence of liquid and gas flow rates on $\mathrm{CO}_{2}$ absorption rate and interfacial area were investigated. Besides, the effects of absorbents on wetting of membrane and the resistances of mass transfer were also discussed.

\section{Kinetic theory}

\subsection{Film model}

The mass transfer between gas and liquid through the hollow fiber membrane contactor occurs in three parts; gas film, 


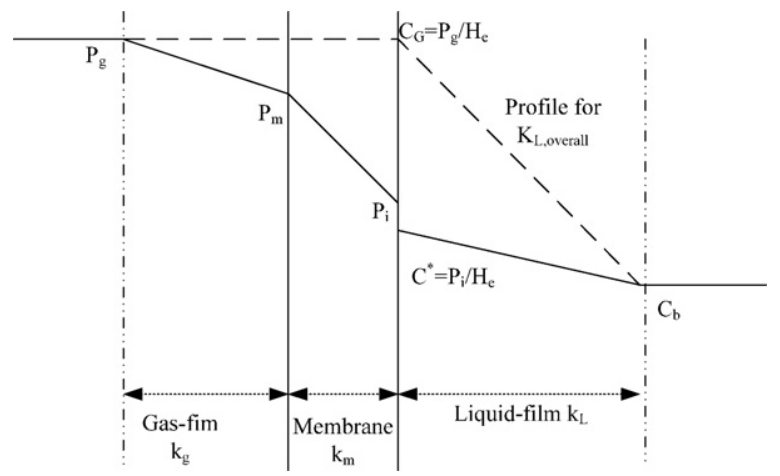

Fig. 1. Film model for mass transfer across an ideal non-wetted membrane.

membrane, and liquid film (Yeon et al., 2003) as shown in Fig. 1. The $\mathrm{CO}_{2}$ flux per unit fiber length at any cross-section, $J$ can be expressed by Eq. (1).

$$
\begin{aligned}
J\left(n \pi d_{\mathrm{i}}\right) & =K_{\mathrm{L}}\left(n \pi d_{\mathrm{i}}\right)\left(\frac{P_{\mathrm{g}}}{H_{\mathrm{e}}}\right)=k_{\mathrm{g}}\left(n \pi d_{\mathrm{i}}\right)\left(P_{\mathrm{g}}-P_{\mathrm{m}}\right) \\
& =\left(\frac{k_{\mathrm{m}}}{R T}\right)\left(n \pi d_{\mathrm{i}}\right)\left(P_{\mathrm{m}}-P_{\mathrm{i}}\right)=k_{\mathrm{L}} E\left(n \pi d_{\mathrm{i}}\right)\left(\frac{P_{\mathrm{i}}}{H_{\mathrm{e}}}\right)
\end{aligned}
$$

where $k_{\mathrm{L}}, k_{\mathrm{m}}$, and $k_{\mathrm{g}}$ indicate the mass transfer coefficients $(\mathrm{m} / \mathrm{s})$ of the liquid phase, membrane, and gas phase, respectively, $K_{\mathrm{L}}$ is overall liquid phase mass transfer coefficient, $n$ is the number of the fiber; $d_{\mathrm{i}}$ and $d_{\mathrm{o}}$ are inside and outside diameter of the fiber: $P_{\mathrm{g}}, P_{\mathrm{i}}$, and $P_{\mathrm{m}}$, are $\mathrm{CO}_{2}$ partial pressures in the bulk gas phase, membrane-liquid interface, and gasmembrane interface, respectively $(\mathrm{kPa}) ; H_{\mathrm{e}}$ is the Henry's constant $\left(\mathrm{m}^{3} \mathrm{kPa} / \mathrm{kmol}\right)$; and $E$ is enhancement factor. The overall resistance in liquid phase mass transfer through the porous hollow fiber membrane contactor can be expressed as the following Eq. (2) (Kreulen et al., 1993).

$$
\frac{1}{K_{\mathrm{L}}}=\left(\frac{d_{\mathrm{i}}}{d_{\mathrm{o}} k_{\mathrm{g}}}\right)\left(\frac{1}{H_{\mathrm{e}}}\right)+\left(\frac{d_{\mathrm{i}}}{d_{\mathrm{o}} k_{\mathrm{m}}}\right)\left(\frac{R T}{H_{\mathrm{e}}}\right)+\frac{1}{E k_{\mathrm{L}}}
$$

If film model for mass transfer is across an ideal non-wetted membrane (Yeon et al., 2003). The overall mass transfer coefficient, $K_{\mathrm{L}}$ can be obtained by Eq. (3).

\subsection{Individual gas-film mass transfer coefficients}

The individual mass transfer coefficient of liquid phase $k_{\mathrm{L}}$ can be predicted using the equation followed (Nii and Takeuchi, 1994; Rangwala, 1996):

$\frac{k_{\mathrm{L}} d_{\mathrm{i}}}{D_{\mathrm{L}}}=1.62\left(\frac{d_{\mathrm{i}}^{2} v_{\mathrm{L}}}{L D_{\mathrm{L}}}\right)^{1 / 3}$

The individual mass transfer coefficient of gas phase used the proposed correlation as followed (Gilliland and Sherwood, 1934):

$$
\frac{k_{\mathrm{g}} d_{\mathrm{e}}}{D_{\mathrm{g}}}=0.023\left(\frac{4 \gamma_{\mathrm{H}} \rho v_{\mathrm{g}}}{\mu_{\mathrm{g}}}\right)^{0.83}\left(\frac{\mu_{\mathrm{g}}}{D_{\mathrm{g}} \rho}\right)^{0.44}
$$

The membrane mass transfer coefficient is predicted using the Eq. (6). Here the effective diffusivity as calculated from the harmonic mean is showed in Eq. (7).

$$
\begin{aligned}
& k_{\mathrm{m}}=\frac{2 D_{\mathrm{e}} \varepsilon}{\tau d_{\mathrm{i}} \ln \left(d_{\mathrm{o}} / d_{\mathrm{i}}\right)} \\
& D_{\mathrm{e}}^{-1}=D_{\mathrm{k}}^{-1}+D_{\mathrm{g}}^{-1}
\end{aligned}
$$

Using the values in Eq. (6) for the fiber used in the hollow fiber module, $k_{\mathrm{m} \text {,gas filled }}$ is estimated as $2.69 \times 10^{-3} \mathrm{~m} / \mathrm{s}$. In the case of liquid filled pores, the effective diffusivity is similar to that of $\mathrm{CO}_{2}$ in the solution $\left(1.49 \times 10^{-9} \mathrm{~m}^{2} / \mathrm{s}\right)$, and $k_{\mathrm{m} \text {,liquid filled }}$ is about $2.62 \times 10^{-7} \mathrm{~m} / \mathrm{s}$. If the pores are partial filled with liquid, then $k_{\mathrm{m}}$ was of the average fractional depth of liquid penetration $\beta$ can be calculated from

$\frac{1}{k_{\mathrm{m}}}=\frac{\beta}{k_{\mathrm{m}, \text { liquid filled }}}+\frac{(1-\beta)}{k_{\mathrm{m}, \text { gas filled }}}$

\subsection{Interfacial reaction rate for $\mathrm{CO}_{2}$ absorption into $\mathrm{PZ}+\mathrm{AMP}+\mathrm{H}_{2} \mathrm{O}$}

For the absorption of $\mathrm{CO}_{2}$ into $\mathrm{PZ}+\mathrm{AMP}+\mathrm{H}_{2} \mathrm{O}$, the overall $\mathrm{CO}_{2}$ reaction rate can then be expressed as follows (Sun et al., 2005):

$$
\begin{aligned}
& r_{\mathrm{ov}}=k_{\mathrm{ov}}\left[\mathrm{CO}_{2}\right] \\
& =k_{2, \mathrm{PZ}}\left[\mathrm{CO}_{2}\right][\mathrm{PZ}]+k_{\mathrm{OH}^{-}}^{*}\left[\mathrm{CO}_{2}\right]\left[\mathrm{OH}^{-}\right]+\frac{[\mathrm{AMP}]\left[\mathrm{CO}_{2}\right]}{\left(1 / k_{2, \mathrm{ANP}}+k_{2, \mathrm{AMP}} k_{\mathrm{H}_{2} \mathrm{O}}\left[\mathrm{OH}^{-}\right] / k_{-1}+k_{2, \mathrm{AMP}} K_{\mathrm{PZ}}[\mathrm{PZ}] / k_{-1}+k_{2, \mathrm{AMP}} k_{\mathrm{AMP}}[\mathrm{AMP}] / k_{-1}\right)}
\end{aligned}
$$

$$
K_{\mathrm{L}} a=\left(\frac{R}{\Delta P_{\mathrm{M}} / H_{\mathrm{e}}}\right)
$$

where $R$ is $\mathrm{CO}_{2}$ absorption rate $\left(\mathrm{kmol} / \mathrm{m}^{3} \mathrm{~s}\right)$ per unit volume of the contactor. where $k_{2, \mathrm{AMP}}$ is the reaction rate constant for formation of a zwitterions from $\mathrm{CO}_{2}$ and AMP, $k_{-1}$ is the reaction rate constant for the reverse reaction of the zwitterion, $k_{\mathrm{H}_{2} \mathrm{O}}, K_{\mathrm{OH}^{-}}, k_{\mathrm{PZ}}, k_{\mathrm{AMP}}$ are the reaction rate constants for subsequent removal proton reaction from a zwitterions by bases: $\mathrm{H}_{2} \mathrm{O}, \mathrm{OH}^{-}, \mathrm{PZ}$ and AMP, respectively. 
Here, the apparent reaction rate constant, $k_{\text {app }}$, is defined as followed

$k_{\mathrm{app}}=k_{\mathrm{ov}}-k_{\mathrm{OH}^{-}}^{*}\left[\mathrm{OH}^{-}\right]=k_{2, \mathrm{PZ}}[\mathrm{PZ}]+\frac{[\mathrm{AMP}]}{\left(1 / k_{2, \mathrm{ANP}}+k_{2, \mathrm{AMP}} k_{\mathrm{H}_{2} \mathrm{O}}\left[\mathrm{OH}^{-}\right] / k_{-1}+k_{2, \mathrm{AMP}} K_{\mathrm{PZ}}[\mathrm{PZ}] / k_{-1}+k_{2, \mathrm{AMP}} k_{\mathrm{AMP}}[\mathrm{AMP}] / k_{-1}\right)}$

\section{Experimental}

\subsection{Materials}

Piperazine and AMP were purchased from Aldrich Chemicals. The membrane contactor used as $\mathrm{CO}_{2}$ absorbers in this study is the polyvinylidinefluoride (PVDF) hollow fibers supported from Pall Co. (UMP-0047R). Details of the hollow fiber were listed in Table 1. Deionized water was used. All chemicals were used without any further purification.

\subsection{Absorption of carbon dioxide}

The experimental set-up for $\mathrm{CO}_{2}$ removal and recovery was shown in Fig. 2. The gas containing $1-15 \%$ of $\mathrm{CO}_{2}$ (balance $\mathrm{N}_{2}$ ) was passed upstream in the tube side of the membrane module, and the absorbent was supplied downstream in the shell side. The absorbents used in this system are mixed solutions of piperazine $0.1-0.4 \mathrm{M}$, and $1 \mathrm{M}$ AMP. The gas flow rate was changed at the range of $100-600 \mathrm{~cm}^{3} / \mathrm{min}$, and the liquid flow rate was changed at the range of $100-400 \mathrm{~cm}^{3} / \mathrm{min}$. The solution was reused after the $\mathrm{CO}_{2}$ dissolved in the solution was totally stripped in the desorption tower connected with the reboiler. The pressure difference of the liquid phase and the gas phase was kept in the range of $2-5$ psig by a needle valve to form the stable gas-liquid interface in the membrane module. The gases coming from the absorption were sampled and analyzed by TCD-GC (GC-14B; Shimadzu) at steady state (about 15-20 min).

\section{Results and discussion}

\subsection{Effects of flow rate on specific surface area}

The objective of this section was to investigate the effective contact areas of this module under the studied conditions. The $\mathrm{N}_{2}-\mathrm{CO}_{2}-\mathrm{H}_{2} \mathrm{O}$ system was used due to the $\mathrm{CO}_{2}$ absorption rate is low by $\mathrm{H}_{2} \mathrm{O}$ solution. The absorption rates of $\mathrm{CO}_{2}$ using water

Table 1

Characteristics of hollow fiber module (UMP-0047R)

\begin{tabular}{lc}
\hline Module o.d. $(\mathrm{mm})$ & 16 \\
Shell i.d. $(\mathrm{mm})$ & 14 \\
Fiber o.d. $(\mathrm{mm})$ & 2.2 \\
Fiber i.d. $(\mathrm{mm})$ & 1.4 \\
Fiber length $(\mathrm{cm})$ & 31.4 \\
Number of fibers & 21 \\
Average pore size $(\mu \mathrm{m})$ & 0.2 \\
Fiber porosity, $\varepsilon(\%)$ & 50 \\
Surface area $\left(\right.$ nominal $\left.\mathrm{m}^{2}\right)$ & 0.02
\end{tabular}

at $30{ }^{\circ} \mathrm{C}$ at various gas and liquid flow rate are shown in Table 2 . It can be seen that the absorption rates in Table 2 are almost independent of gas flow rates, revealing that the resistance of gas-film diffusion is insignificant compared to that of liquidfilm diffusion in $\mathrm{N}_{2}-\mathrm{CO}_{2}-\mathrm{H}_{2} \mathrm{O}$ system. Rangwala (1996) and Yang and Cussler (1986) have ever reported similar trend for air- $\mathrm{CO}_{2}-\mathrm{H}_{2} \mathrm{O}$ system. The pores will be gas-filled due to the fact that PVDF membrane is hydrophobic. The gas-filled membrane results in a neglect resistance of diffusion in pores compared to that of liquid-film. Thus, the measured overall $K_{\mathrm{L}}$ will be nearly equal to $k_{\mathrm{L}}$ in Eq. (2). The effective gas-liquid contact area per volume can be calculated from the measured values of $K_{\mathrm{L}} a$ from Eq. (3) (Rangwala, 1996). The calculated effective gas-liquid contact areas are below the geometrical areas (nominal contact areas $=0.02 \mathrm{~m}^{2}$ ) shown as Fig. 3. As shown in Fig. 3, the effective gas-liquid contact areas per volume are influenced on the fluid flow rates. These results indicated that the greater effective contact areas per volume will be obtained at higher fluid velocities. So we suggested that the fluid flow rate was operated at the condition of $N_{\mathrm{Re}}>15$ to prevent losing the effective specific contact areas.

\subsection{Effect of operational parameters on absorption rate}

Figs. 4-6 showed the $\mathrm{CO}_{2}$ absorption rate in PVDF membrane modules using the mixed solution of AMP and $\mathrm{PZ}$ as absorbent. The $\mathrm{CO}_{2}$ absorption rate increased with both gas and liquid flow rates initially, and then reached a plateau shown as Figs. 4 and 5. It was because that an increase of

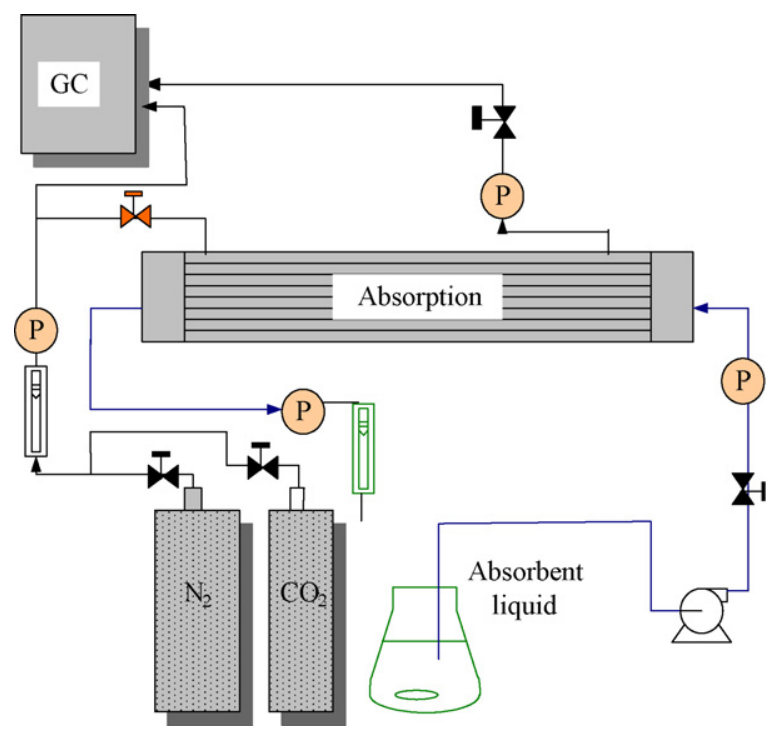

Fig. 2. Experimental set-up. 
Table 2

Absorption rate of $\mathrm{CO}_{2}$ with $\mathrm{H}_{2} \mathrm{O}$ in hollow fiber

\begin{tabular}{lll}
\hline$Q_{\mathrm{G}}\left(\mathrm{cm}^{3} / \mathrm{min}\right)$ & $Q_{\mathrm{L}}\left(\mathrm{cm}^{3} / \mathrm{min}\right)$ & $R\left(\mathrm{kmol} / \mathrm{m}^{3} \mathrm{~s}\right)$ \\
\hline 357 & 100 & $8.4 \times 10^{-7}$ \\
& 200 & $1.1 \times 10^{-6}$ \\
& 300 & $1.2 \times 10^{-6}$ \\
& 400 & $1.4 \times 10^{-6}$ \\
429 & 100 & $8.3 \times 10^{-7}$ \\
& 200 & $9.7 \times 10^{-7}$ \\
& 300 & $1.2 \times 10^{-6}$ \\
& 400 & $1.4 \times 10^{-6}$ \\
499 & 100 & $8.5 \times 10^{-7}$ \\
& 200 & $9.9 \times 10^{-7}$ \\
& 300 & $1.2 \times 10^{-6}$ \\
400 & $1.4 \times 10^{-6}$ \\
\hline
\end{tabular}

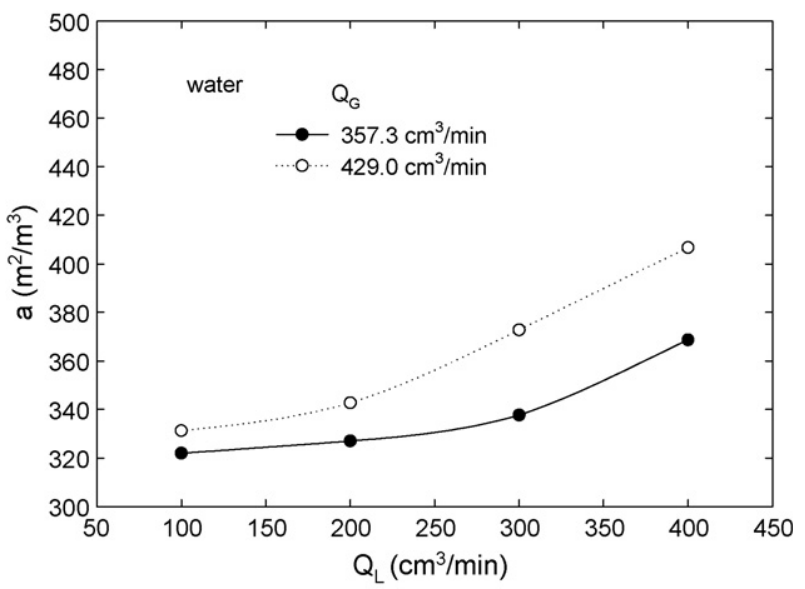

Fig. 3. The specific area at different fluid flow rates of hollow fiber module.

velocity in hollow fiber can reduce the resistance of stagnantlayer diffusion under laminar flow. Yeon et al. have ever investigated the $\mathrm{CO}_{2}$ absorption in PVDF and PTFE hollow fiber membrane using single absorbent (MEA) (Yeon et al., 2003). They also found the similar behavior that the $\mathrm{CO}_{2}$ flux increased with an increase of liquid velocity and that increased initially with an increase of gas velocity. Wang et al. (2004)

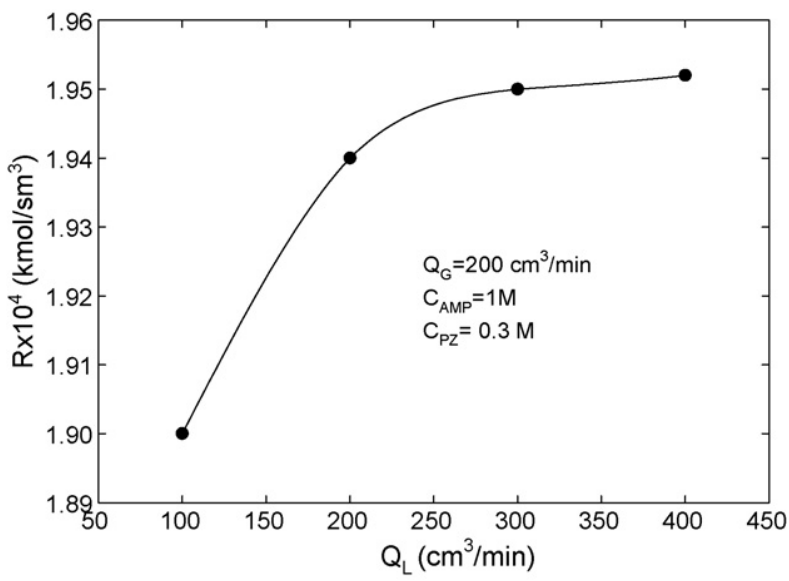

Fig. 4. $\mathrm{CO}_{2}$ absorption rates at various liquid flow rate in HFMC.

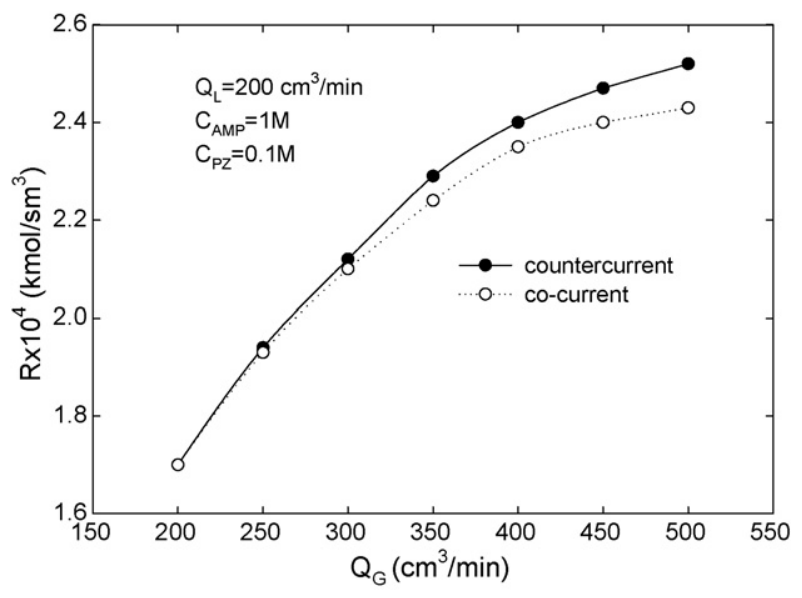

Fig. 5. $\mathrm{CO}_{2}$ absorption rates at various gas flow rate in HFMC.

studied the $\mathrm{CO}_{2}$ capture by three typical amines solutions in hollow fiber membrane contactors. They reported that $\mathrm{CO}_{2}$ absorption flux in MDEA solution is virtually unaffected by the liquid flow velocity. However, that for both AMP and DEA solutions, the $\mathrm{CO}_{2}$ absorption flux increased with an increase in liquid flow velocity. It was due to that the reaction rate of $\mathrm{CO}_{2}$ with MDEA was much slower than that of AMP and DEA (Wang et al., 2004).

As shown in Fig. 6, the $\mathrm{CO}_{2}$ absorption rate was $1.8 \times 10^{-4} \mathrm{kmol} / \mathrm{m}^{3} \mathrm{~s}$ with the AMP $(1 \mathrm{M})$ solution and that was enhanced to $2.4 \times 10^{-4} \mathrm{kmol} / \mathrm{m}^{3} \mathrm{~s}$ by the addition of $0.1 \mathrm{M}$ PZ promoter at $Q_{\mathrm{G}}=400 \mathrm{~cm}^{3} / \mathrm{min}$ and $Q_{\mathrm{L}}=200 \mathrm{~cm}^{3} / \mathrm{min}$. Although the $\mathrm{CO}_{2}$ absorption rate was already reaching $1.3 \times 10^{-4} \mathrm{kmol} / \mathrm{m}^{3} \mathrm{~s}$ with only PZ $(0.1 \mathrm{M})$ solution, the PZ was unflavored used individually due to its instability of carbamate. One reason for choosing the mixture of AMP and PZ was that AMP has higher cyclic capacities of $\mathrm{CO}_{2}$ than conventional primary and secondary amines.

Fig. 7 showed the effect of $\mathrm{PZ}$ concentration on the $\mathrm{CO}_{2}$ absorption rate. It can be seen the $\mathrm{CO}_{2}$ absorption rate increased with increasing $\mathrm{PZ}$ concentration first and then reached a maximum. It was unusual to find that the $\mathrm{CO}_{2}$ absorption rate drop beyond 0.3 M PZ concentration. It was likely that the

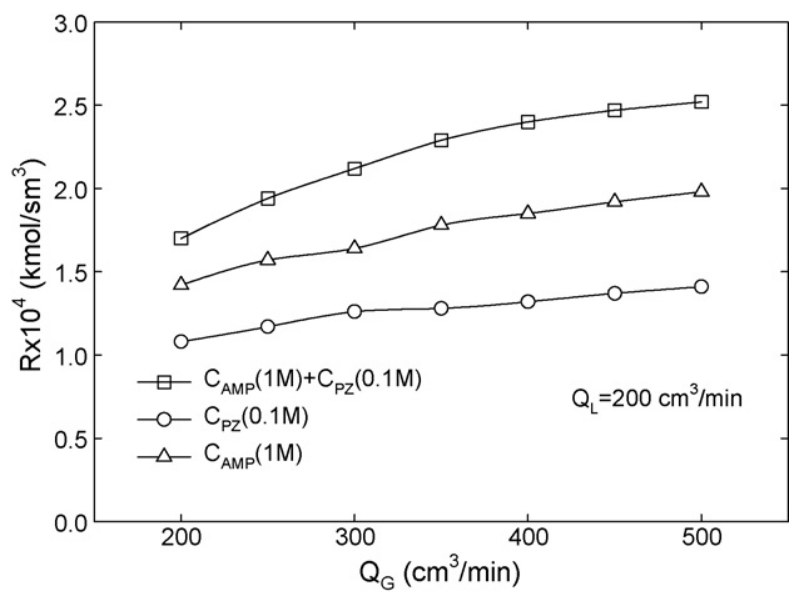

Fig. 6. $\mathrm{CO}_{2}$ absorption rates at various absorbents in HFMC. 


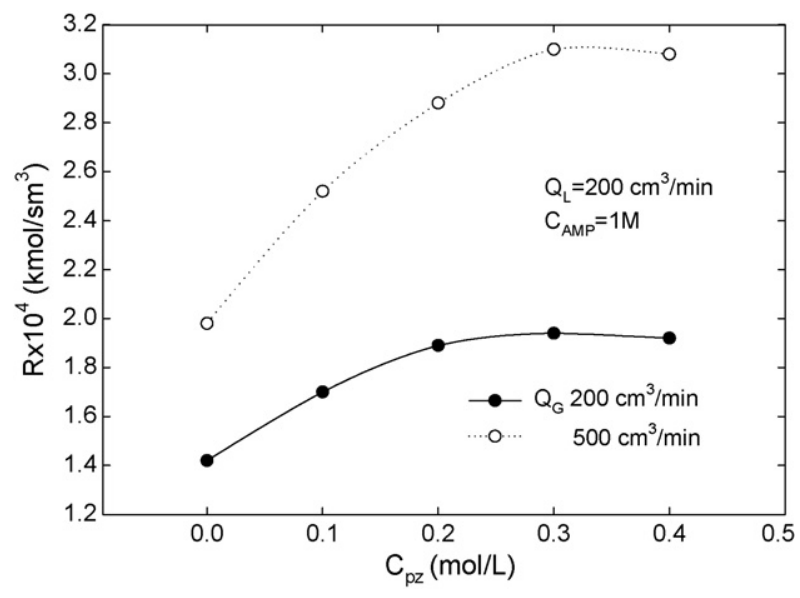

Fig. 7. $\mathrm{CO}_{2}$ absorption rates at different $\mathrm{PZ}$ concentration in HFMC.

higher viscosity of the aqueous solution (1 M AMP $+0.4 \mathrm{M}$ $\mathrm{PZ}$ ) reduced the $\mathrm{CO}_{2}$ absorption rate. The study using ethanolamine mixed with $\mathrm{PZ}$ as absorbent was found by Yeon et al. (2004). They investigated the $\mathrm{CO}_{2}$ absorption rate using the mixed absorbent of PZ and TEA and reported that the $\mathrm{CO}_{2}$ absorption rate was 8 times higher than that of the TEA alone. They thought that these results were caused by the difference of the reaction mechanism between PZ and TEA (Yeon et al., 2004). Because it was hard to compare the $\mathrm{CO}_{2}$ absorption rate with two kinds of mixed absorbents with different pore size PVDF membrane modules. We also tested the $\mathrm{CO}_{2}$ absorption with the mixed absorbents of TEA $(1 \mathrm{M})$ and PZ $(0.1 \mathrm{M})$. The $\mathrm{CO}_{2}$ absorption rate using TEA $(1 \mathrm{M})$ and $\mathrm{PZ}(0.1 \mathrm{M})$ was found to be $1.3 \times 10^{-4} \mathrm{kmol} / \mathrm{m}^{3}$ s. So in our system, the $\mathrm{CO}_{2}$ absorption rate by absorbents of AMP $(1 \mathrm{M})$ and PZ $(0.1 \mathrm{M})$ $\left(R=2.52 \times 10^{-4} \mathrm{kmol} / \mathrm{m}^{3} \mathrm{~s}\right)$ was better than that of by TEA $(1 \mathrm{M})$ and $\mathrm{PZ}(0.1 \mathrm{M})$.

\subsection{Effect of membrane wetting on mass transfer coefficient}

Wetting occurs when the liquid solutions enter the pores of the membrane and has been shown to increase the resistance to mass transfer. The ratio of wetting of membrane $\beta$ can be calculated by Eq. (8). The measured $k_{\mathrm{m}}$ was obtained by the methods described in earlier literature (Rangwala, 1996). We

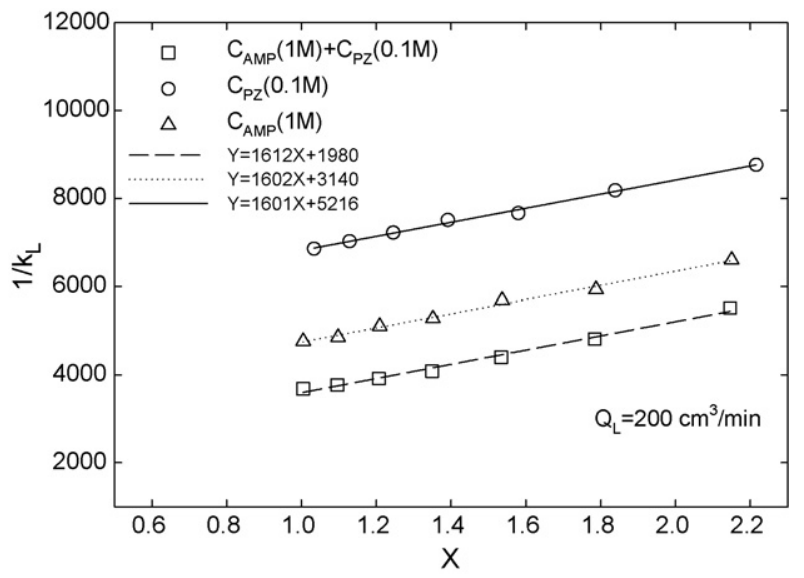

Fig. 8. The plot of $1 / K_{\mathrm{L}}$ vs. $X=\left[\left(P_{\mathrm{BM}} / P_{\mathrm{T}}\right)\left(d_{\mathrm{i}} / d_{\mathrm{o}}\right)\right] /\left[H_{\mathrm{e}} v_{\mathrm{g}}^{0.83}\right]$.

plotted the $1 / K_{\mathrm{L}}$ vs. $X=\left[\left(P_{\mathrm{BM}} / P_{\mathrm{T}}\right)\left(d_{\mathrm{i}} / d_{\mathrm{o}}\right)\right] /\left[H_{\mathrm{e}} v_{\mathrm{g}}^{0.83}\right]$ shown in Fig. $8\left(R^{2}=0.999\right)$ with different PZ and AMP concentrations. Those parameters used here were referred to our previous paper (Sun et al., 2005). The high $R^{2}$ indicated the correctness of this method. The linear relationship was obtained and the intercept of the line would be used to calculate the value of $k_{\mathrm{m}}$. According to the Eq. (8), $\beta$ could be obtained shown in Table 3. It can be seen that the absorbents containing PZ had higher $\beta$ value than that using single AMP absorbent. It is probable that PZ was more attractive to PVDF membrane than ethanolamine. It was confirmed by the data of contact angle (Table 3). The $\beta$ values increased with decreasing contact angle $\theta$ except for PZ (Fig. 9(a)). The $\beta$ values decreased with increasing PZ concentration except for $0.4 \mathrm{PZ}$. It was because that the viscosity of absorbent increased with PZ concentration shown in Fig. 9(b). The higher liquid viscosity will lead to a lower penetration ratio of liquid into the pore of membrane fiber. But both of the exception mentioned above indicated that the $\beta$ value resulted from the influences of those factors. So the wetting ratio of membrane was affected not only on the hydrophobicity of membrane but also the affinity between the absorbent and membrane and viscosity of absorbent solution. For the reason to clarify the influence of characteristic of wetting, we tested another alkanolamine MDEA (i.e. $N$-methyldiethanolamine). It was due to its higher viscosity and the calculated $\beta$ values also listed in Table 3. In comparison of MDEA (1 M) + PZ (0.1 M)

Table 3

Wetting ratio of $\beta$ at various absorbent in PVDF membrane

\begin{tabular}{|c|c|c|c|c|c|c|}
\hline$C_{\mathrm{AMP}}\left(\mathrm{kmol} / \mathrm{m}^{3}\right)$ & $C_{\mathrm{PZ}}\left(\mathrm{kmol} / \mathrm{m}^{3}\right)$ & $k_{\mathrm{m}}(\mathrm{m} / \mathrm{s})$ & $\beta(\%)$ & $\mu(\mathrm{mPa} \mathrm{s})$ & $E$ & $\theta\left(^{\circ}\right)$ \\
\hline 1 & 0.0 & $7.81 \times 10^{-4}$ & $3.65 \times 10^{-2}$ & 1.1 & 26.6 & $\overline{90.4}$ \\
\hline 1 & 0.1 & $5.00 \times 10^{-4}$ & $6.09 \times 10^{-2}$ & 1.20 & 64.8 & 87.5 \\
\hline 1 & 0.2 & $6.34 \times 10^{-4}$ & $4.19 \times 10^{-2}$ & 1.26 & 88.3 & 83.8 \\
\hline 1 & 0.3 & $7.15 \times 10^{-4}$ & $3.42 \times 10^{-2}$ & 1.32 & 107 & 82.6 \\
\hline 1 & 0.4 & $6.54 \times 10^{-4}$ & $3.50 \times 10^{-2}$ & 1.39 & 127 & 79.7 \\
\hline 0 & 0.1 & $1.09 \times 10^{-4}$ & $3.97 \times 10^{-1}$ & 0.83 & 64.3 & 76.5 \\
\hline$C_{\mathrm{MDEA}}\left(\mathrm{kmol} / \mathrm{m}^{3}\right)$ & $C_{\mathrm{PZ}}\left(\mathrm{kmol} / \mathrm{m}^{3}\right)$ & $k_{\mathrm{m}}(\mathrm{m} / \mathrm{s})$ & $\beta(\%)$ & $\mu(\mathrm{mPa} \mathrm{s})$ & E & $\theta\left(^{\circ}\right)$ \\
\hline 1 & 0.0 & $7.79 \times 10^{-4}$ & $3.39 \times 10^{-2}$ & 1.2 & 4 & 96.3 \\
\hline 1 & 0.1 & $4.77 \times 10^{-4}$ & $5.91 \times 10^{-2}$ & 1.24 & 55.8 & 94.1 \\
\hline
\end{tabular}



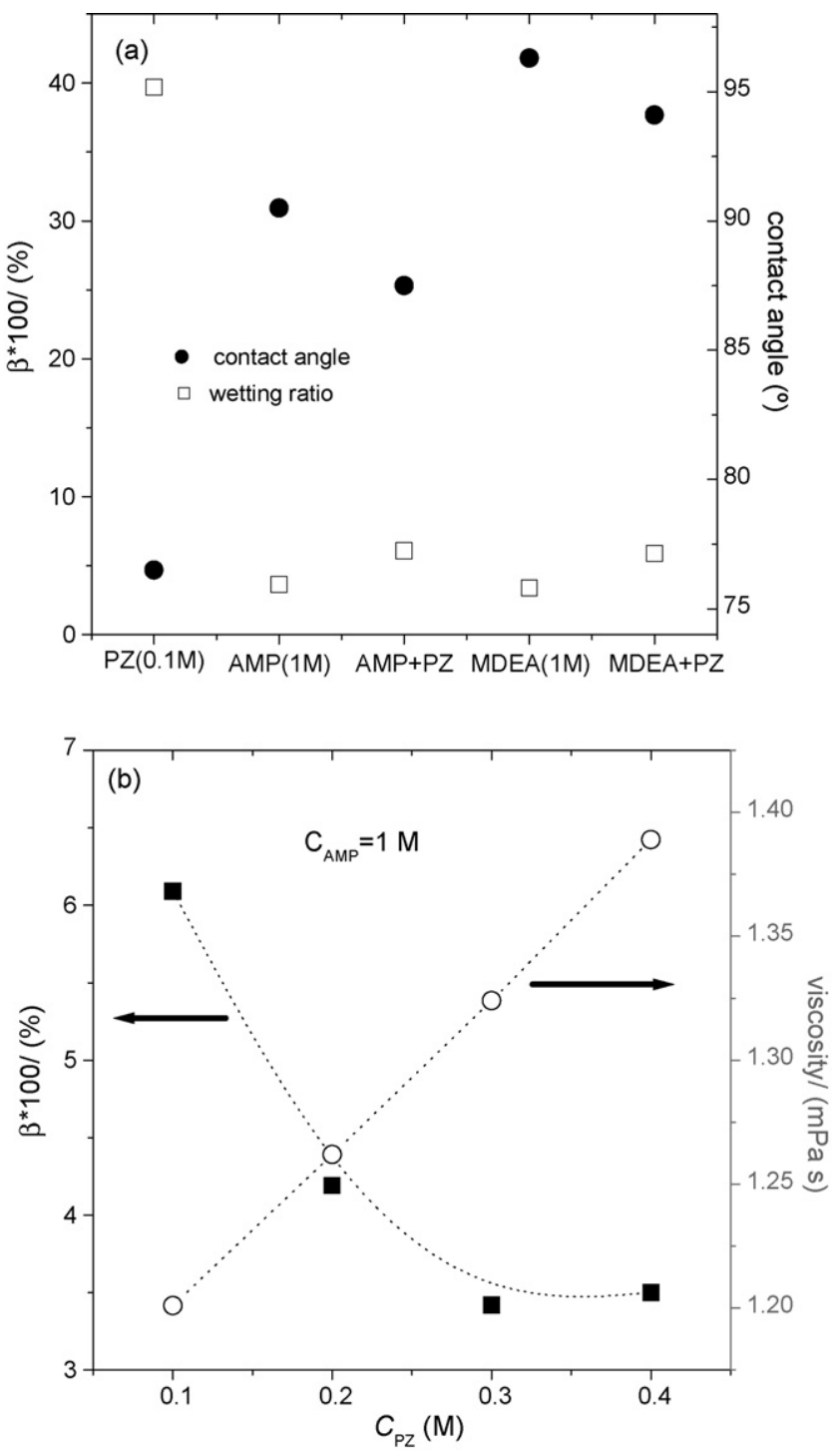

Fig. 9. (a) The $\beta$ values and viscosities of various absorbents; (b) the $\beta$ values and contact angle of various absorbents.

with $\operatorname{AMP}(1 \mathrm{M})+\mathrm{PZ}(0.1 \mathrm{M})$, the former had less wetting ratio than that of the latter. It is due to that the viscosity of MDEA was greater that that of AMP. This phenomenon was also found in the previous report (de Montigny et al., 2006). They examined the $\mathrm{CO}_{2}$ absorption using aqueous solutions of monoethanolamine (MEA) and AMP with PP and PTFE. They observed that a poorer performance of the PP membranes in AMP solution than that of PP membrane in MEA solution. One possible explanation is PP membrane could be easily wetted by AMP solution.

Compared the $\beta$ value with other study, Shimada et al. (2006) studied the $\mathrm{CO}_{2}$ absorption using sterically hindered methyl aminoethanol (MAE) in polytetrafluoroethylene (PTFE). They found the liquid penetration into pores of hydrophobic microporous hollow fibers was about 0.06$0.116 \%$. Compared to ours, the lower $\beta$ value was obtained by us due to the pore size of ours of $0.2 \mu \mathrm{m}$ was smaller that of Shimada et al. $(0.45 \mu \mathrm{m})$.

The resistance of membrane diffusion is very important in hollow fiber process. The mass transfer coefficients of membrane $k_{\mathrm{m}}$ were shown in Table 3 . It can be seen that the $k_{\mathrm{m}}$ using different absorbents decreased in the following order of $1 \mathrm{M} \mathrm{AMP}>1 \mathrm{M} \mathrm{AMP}+0.3 \mathrm{M} \mathrm{PZ}>1 \mathrm{M} \mathrm{AMP}+0.4 \mathrm{M}$ $\mathrm{PZ}>1 \mathrm{M} \mathrm{AMP}+0.2 \mathrm{M} \mathrm{PZ}>1 \mathrm{M} \mathrm{AMP}+0.1 \mathrm{M} \mathrm{PZ}$. This order is a little inconsistent with that of $\beta$ value. It is because that $k_{\mathrm{m}}$ is not only dependent on the $\beta$ value but also on the diffusivity of liquid that penetrating into the pore of membrane. The diffusivity of liquid is a function of the viscosity (shown in Table 3 ). Here the average $k_{\mathrm{m}}$ was $7 \times 10^{-4} \mathrm{~m} / \mathrm{s}\left(d_{\mathrm{p}}=0.2 \mu \mathrm{m}\right)$, it is greater than that by Rangwala (1996) using PP membrane $\left(k_{\mathrm{m}}=3-6.5 \times 10^{-4} \mathrm{~m} / \mathrm{s}\right.$, $\left.d_{\mathrm{p}}=0.015 \mu \mathrm{m}\right)$. However, the $k_{\mathrm{m}}$ is smaller than that using PVDF membrane $\left(10 \times 10^{-4} \mathrm{~m} / \mathrm{s}, d_{\mathrm{p}}=0.03 \mu \mathrm{m}\right)$, but larger than that using PTFE membrane $\left(5 \times 10^{-4} \mathrm{~m} / \mathrm{s}, d_{\mathrm{p}}=1 \mu \mathrm{m}\right)$ by Yeon et al. (2003). It is due to the difference of pore sizes and absorbents.

\subsection{Analysis of resistance of mass transfer}

To compare the resistance of mass transfer in hollow fiber, we express overall resistance as $1 / K_{\mathrm{L}}$ in Eq. (2).

The fractional resistance of each step to the overall process can be calculated, e.g., $\Delta_{M}$ in hollow fiber module, by

$\Delta_{\mathrm{M}}=\frac{R_{\mathrm{M}}}{\left(R_{\mathrm{G}}+R_{\mathrm{M}}+R_{\mathrm{L}}\right)}$

$R_{\mathrm{M}}, R_{\mathrm{G}}$, and $R_{\mathrm{L}}$ were represented as the resistances of membrane, gas-film and liquid-film diffusion, respectively (i.e. the terms of $\left(d_{\mathrm{i}} / d_{\mathrm{o}} k_{\mathrm{m}}\right)\left(R T / H_{\mathrm{e}}\right), \quad\left(d_{\mathrm{i}} / d_{\mathrm{o}} k_{\mathrm{g}}\right)\left(1 / H_{\mathrm{e}}\right)$ and $\left.1 / E k_{\mathrm{L}}\right)$. Table 4 showed the calculated mass transfer coefficients and the fractional resistance calculated at various absorbents, flow rates and concentrations. Comparing them, we can find the rate-controlling steps. In this process, the resistance of membrane diffusion was predominated only when single PZ (1 M) and mixed of TEA (1 M) + PZ (0.1 M) as absorbents under the ranges studied. It can be seen that both absorbents had the low $\mathrm{CO}_{2}$ absorption rates showing in Table 4. The diffusion resistance of gas-film was important as we used the mixed absorbent of AMP and PZ, which increased with increasing the PZ concentration. A high resistance of gas-film diffusion was ever mentioned by Rangwala (1996). He investigated the $\mathrm{CO}_{2}$ absorption rate using polypropylene (PP) hollow fiber (X-10). In air- $\mathrm{CO}_{2}-$ aq. DEA $(0.5 \mathrm{M})$ system, he found the membrane and gas phase resistance to be 20 and $33.8 \%$. In air- $\mathrm{CO}_{2}-$ aq. $\mathrm{NaOH}$ ( $2 \mathrm{M}$ ) system in $0.051 \mathrm{~m}$ HFMM, he found the membrane and gas phase resistance to be 35 and $60 \%$. Shimada et al. (2006) studied the $\mathrm{CO}_{2}$ absorption using MAE in polytetrafluoroethylene. They reported that the resistance of membrane diffusion amounted to $76-80 \%$ of the total resistance. Here, the AMP (1 M) absorbent had the smallest resistance of membrane diffusion due to its low $\beta$ value. The resistance of liquid-film diffusion decreased as an increase of the PZ concentration. At the same time, the resistances of gas-film diffusion increased with increasing $\mathrm{PZ}$ concentration. It was due to that the enhancement factor $(E)$ increased with 
Table 4

The fractional resistances and absorption rate of $\mathrm{CO}_{2}$ in $\mathrm{HFMC}$

\begin{tabular}{|c|c|c|c|c|c|}
\hline Absorbent & $\left(1 / K_{\mathrm{L}}\right)_{\text {measured }}(\mathrm{m} / \mathrm{s})$ & $1 / E k_{\mathrm{L}}(\mathrm{m} / \mathrm{s})$ & & $\left(d_{\mathrm{i}} / d_{\mathrm{o}} k_{\mathrm{m}}\right)\left(R T / H_{\mathrm{e}}\right)(\mathrm{m} / \mathrm{s})$ & $\left(d_{\mathrm{i}} / d_{\mathrm{o}} k_{\mathrm{g}}\right)\left(1 / H_{\mathrm{e}}\right)(\mathrm{m} / \mathrm{s})$ \\
\hline PZ (0.1 M) & 6913 & 943 & & 4316 & 1655 \\
\hline $\operatorname{AMP}(1 \mathrm{M})$ & 3245 & 1052 & & 584 & 1609 \\
\hline TEA (1 M) + PZ (0.1 M) & 7019 & 1913 & & 3313 & 1793 \\
\hline $\operatorname{AMP}(1 \mathrm{M})+\mathrm{PZ}(0.1 \mathrm{M})$ & 3609 & 1080 & & 910 & 1620 \\
\hline $\mathrm{AMP}(1 \mathrm{M})+\mathrm{PZ}(0.2 \mathrm{M})$ & 3161 & 839 & & 719 & 1603 \\
\hline $\mathrm{AMP}(1 \mathrm{M})+\mathrm{PZ}(0.3 \mathrm{M})$ & 2985 & 716 & & 636 & 1631 \\
\hline AMP (1 M) + PZ (0.4 M) & 2954 & 641 & & 698 & 1615 \\
\hline MDEA (1 M) & 3251 & 1106 & & 571 & 1573 \\
\hline MDEA (1 M) + PZ (0.1 M) & 3623 & 1143 & & 892 & 1587 \\
\hline Absorbent & $R\left(\mathrm{kmol} / \mathrm{m}^{3} \mathrm{~s}\right)$ & & $\Delta_{\mathrm{L}}(\%)$ & $\Delta_{\mathrm{M}}(\%)$ & $\Delta_{\mathrm{G}}(\%)$ \\
\hline PZ (0.1 M) & $1.41 \times 10^{-4}$ & & 14 & 62 & 24 \\
\hline AMP (1 M) & $1.98 \times 10^{-4}$ & & 32 & 18 & 50 \\
\hline TEA $(1 \mathrm{M})+\mathrm{PZ}(0.1 \mathrm{M})$ & $1.30 \times 10^{-4}$ & & 27 & 47 & 25 \\
\hline $\mathrm{AMP}(1 \mathrm{M})+\mathrm{PZ}(0.1 \mathrm{M})$ & $2.52 \times 10^{-4}$ & & 30 & 25 & 45 \\
\hline $\mathrm{AMP}(1 \mathrm{M})+\mathrm{PZ}(0.2 \mathrm{M})$ & $2.88 \times 10^{-4}$ & & 26 & 23 & 51 \\
\hline $\operatorname{AMP}(1 \mathrm{M})+\mathrm{PZ}(0.3 \mathrm{M})$ & $3.10 \times 10^{-4}$ & & 24 & 21 & 54 \\
\hline $\operatorname{AMP}(1 \mathrm{M})+\mathrm{PZ}(0.4 \mathrm{M})$ & $3.08 \times 10^{-4}$ & & 21 & 23 & 54 \\
\hline MDEA (1 M) & $0.45 \times 10^{-4}$ & & 34 & 18 & 48 \\
\hline $\operatorname{MDEA}(1 \mathrm{M})+\mathrm{PZ}(0.1 \mathrm{M})$ & $2.36 \times 10^{-4}$ & & 32 & 25 & 43 \\
\hline
\end{tabular}

$Q_{\mathrm{G}}=500, Q_{\mathrm{L}}=200\left(\mathrm{~cm}^{3} / \mathrm{min}\right)$.

increasing the $\mathrm{PZ}$ concentration. The $E$ values were also listed in Table 3 (Sun et al., 2005).

The fractional resistances at various flow rates were shown in Table 5. It was found that the $\Delta_{\mathrm{G}}$ decreased with increasing gas phase flow rates and $\Delta_{\mathrm{L}}$ and $\Delta_{\mathrm{M}}$ increased with increasing gas phase flow rates. Such results were expected because stagnant-layer of gas would be reduced with increasing gas flow rates.

As mentioned before, the parameter of penetration ratio was important in the resistance of membrane. However, the enhancement factor $(E)$ of absorbents was also significant on the resistance of liquid phase. So the absorption rate of $\mathrm{CO}_{2}$ with various absorbents in PVDF hollow fiber was also seen in Table 4. As observed in Table 4, the $\mathrm{CO}_{2}$ absorption rate with blended absorbents was higher than that with single absorbent. Besides, the $\mathrm{CO}_{2}$ absorption rate using AMP was better than that using TEA. The existence of PZ leaded to a higher wetting ratio, but it indeed had a higher $\mathrm{CO}_{2}$ absorption rate. Although, the criteria of absorbent is high reactivity ( $\mathrm{Li}$ and Chen, 2005), the effects of interaction of absorbent and membrane cannot be neglected.

Table 5

The fractional resistances and absorption rate of $\mathrm{CO}_{2}$ in HFMC

\begin{tabular}{lllll}
\hline$Q_{\mathrm{G}}\left(\mathrm{cm}^{3} / \mathrm{min}\right)$ & $R\left(\mathrm{kmol} / \mathrm{m}^{3} \mathrm{~s}\right)$ & $\Delta_{\mathrm{L}}(\%)$ & $\Delta_{\mathrm{M}}(\%)$ & $\Delta_{\mathrm{G}}(\%)$ \\
\hline 200 & $1.70 \times 10^{-4}$ & 19.8 & 16.7 & 63.5 \\
250 & $1.94 \times 10^{-4}$ & 22.2 & 18.7 & 59.1 \\
300 & $2.12 \times 10^{-4}$ & 24.2 & 20.4 & 55.2 \\
350 & $2.29 \times 10^{-4}$ & 25.9 & 21.8 & 52.2 \\
400 & $2.40 \times 10^{-4}$ & 27.4 & 23.1 & 49.5 \\
450 & $2.47 \times 10^{-4}$ & 28.7 & 24.2 & 47.0 \\
500 & $2.52 \times 10^{-4}$ & 29.9 & 25.2 & 44.9 \\
\hline
\end{tabular}

$Q_{\mathrm{L}}=200\left(\mathrm{~cm}^{3} / \mathrm{min}\right), C_{\mathrm{AMP}}=1 \mathrm{M}, C_{\mathrm{PZ}}=0.1 \mathrm{M}$.

\section{Conclusions}

The gas absorption process for removing $\mathrm{CO}_{2}$ can be carried out in a PVDF hollow fiber membrane contactor system. The $\mathrm{CO}_{2}$ absorption rate increased with increasing the liquid, gas flow rates and absorbent concentrations. The effective contact areas per volume were influenced by operational flow rate. The effects of viscosity of absorbents and contact angle could not be ignored. The addition of promoter (PZ) not only enhanced the $\mathrm{CO}_{2}$ absorption rate but also increased the viscosity of absorbent solution. The fractional resistance of membrane diffusion is below $25 \%$ by absorbents of AMP and PZ.

\section{Acknowledgement}

We thank the National Science Council of the Republic of China for financial support (NSC 95-2221-E-253-016).

\section{References}

Alper, E., "Reaction Mechanism and Kinetics of Aqueous Solutions of 2Amino-2-methyl-1-propanol and Carbon Dioxide," Ind. Eng. Chem. Res., 29, 1725 (1990).

Appl, M., U. Wagner, H. J. Henrici, K. Kuessner, K. Voldamer, and E. Fuerest, "Removal of $\mathrm{CO}_{2}$ and/or $\mathrm{H}_{2} \mathrm{~S}$ and/or COS from Gas Containing These Constituents," U.S. Patent, 4, 336, 233 (1982).

Bishnoi, S. and G. T. Rochelle, "Absorption of Carbon Dioxide into Aqueous Piperazine: Reaction Kinetics, Mass Transfer and Solubility," Chem. Eng. Sci., 55, 5531 (2000).

Chakraborty, A. K., G. Astarita, and K. B. Bischoff, " $\mathrm{CO}_{2}$ Absorption in Aqueous Solutions of Hindered Amines," Chem. Eng. Sci., 41, 997 (1986).

Chakravarty, T., U. K. Phukan, and R. H. Weiland, "Reaction of Acid Gases with Mixtures of Amines," Chem. Eng. Prog., 81, 32 (1985).

de Montigny, D., P. Tontiwachwuthikul, and A. Chakma, "Using Polypropylene and Polytetrafluoroethylene Membranes in a Membrane Contactor for $\mathrm{CO}_{2}$ Absorption," J. Membr. Sci., 277, 99 (2006). 
Desideri, U. and A. Paolucci, "Performance Modeling of a Carbon Dioxide Removal System for Power Plants," Energy Convers. Manag., 40, 1899 (1999).

Gabelman, A. and S. T. Hwang, "Hollow Fiber Membrane Contactors," $J$. Membr. Sci., 159, 61 (1999).

Gilliland, E. R. and T. K. Sherwood, "Diffusion of Vapors into Air Streams," Ind. Eng. Chem., 26, 516 (1934).

Kreulen, H., C. A. Smolders, G. F. Versteeg, and W. P. M. van Swaaij, "Microporous Hollow Fiber Membranes as Gas-Liquid Contactors. Part 2. Mass Transfer with Chemical Reaction," J. Membr. Sci., 78, 217 (1993).

Li, M. H. and Y. C. Lie, "Densities and Viscosities of Solutions Monoethanlamine $N$-Methyldiethanolamine Water and Monoethanolamine 2-Amino2-methyl-1-propanol Water," J. Chem. Eng. Data, 39, 444 (1994).

$\mathrm{Li}$, J. L. and B. H. Chen, "Review of $\mathrm{CO}_{2}$ Absorption Using Chemical Solvents in Hollow Fiber Membrane Contactors," Sep. Purif. Technol., 41, 109 (2005).

Nii, S. and H. Takeuchi, "Removal of $\mathrm{CO}_{2}$ and/or $\mathrm{SO}_{2}$ from Gas Streams by a Membrane Absorption Method," Gas Sep. Purif., 8, 107 (1994).

Rangwala, H. A., "Absorption of Carbon Dioxide into Aqueous Solutions Using Hollow Fiber Membrane Contactors," J. Membr. Sci., 112, 229 (1996).

Saha, A. K., S. S. Bandyopadhyay, and A. K. Biswas, "Kinetics of Absorption of $\mathrm{CO}_{2}$ into Aqueous Solutions of 2-Amino-2-methyl-1-propanol," Chem. Eng. Sci., 50, 3587 (1995).

Satori, G. and D. W. Savage, "Sterically Hindered Amines for $\mathrm{CO}_{2}$ Removal from Gases," Ind. Eng. Chem. Fundam., 22, 239 (1983).

Seo, D. J. and W. H. Hong, "Solubilities of Carbon Dioxide in Aqueous Mixtures of Diethanolamine and 2-Amino-2-methyl-1-propanol," J. Chem. Eng. Data, 41, 258 (1996).

Shimada, K., I. N. Seekkuarachchi, and H. Kumazawa, "Absorption of $\mathrm{CO}_{2}$ into Aqueous Solutions of Sterically Hindered Methyl Aminoethanol Using a Hydrophobic Microporous Hollow Fiber Contained Contactors," Chem. Eng. Commun., 193, 38 (2006).

Song, J. H., S. B. Park, J. H. Yoon, and H. Lee, "Densities and Viscosities of Monoethanolamine + Ethylene Glycol + Water," J. Chem. Eng. Data, 41, 1152 (1996).

Sun, W. C., C. B. Yong, and M. H. Li, "Kinetics of the Absorption of Carbon Dioxide into Mixed Aqueous Solutions of 2-Amino-2-methyl-1-propanol and Piperazine," Chem. Eng. Sci., 60, 503 (2005).

Versteeg, G. F. and W. P. M. van Swaaij, "Solubility and Diffusivity of Acid Gases $\left(\mathrm{CO}_{2}, \mathrm{~N}_{2} \mathrm{O}\right)$ in Aqueous Alkanolamine Solutions," J. Chem. Eng. Data, 33, 29 (1988).

Wang, R., D. F. Li, and D. T. Liang, "Modeling of $\mathrm{CO}_{2}$ Capture by Three Typical Amine Solutions in Hollow Fiber Membrane Contactors," Chem. Eng. Process., 43, 849 (2004).

Xiao, J., C. W. Li, and M. H. Li, "Kinetics of Absorption of Carbon Dioxide into Aqueous Solutions of 2-Amino-2-methyl-1-propanol + Monoethanolamine," Chem. Eng. Sci., 55, 161 (2000).

Xu, G. W., C. F. Zhang, S. J. Qin, W. H. Gao, and H. B. Liu, "Gas-Liquid Equilibrium in $\mathrm{CO}_{2}-\mathrm{MDEA}-\mathrm{H}_{2} \mathrm{O}$ System and the Effect of Piperazine on It," Ind. Eng. Chem. Res., 37, 1473 (1998).

Xu, G. W., C. F. Zhang, S. J. Qin, and Y. H. Wang, "Kinetics Study on Absorption of Carbon Dioxide into Solutions of Activated Methyldiethanolamine," Ind. Eng. Chem. Res., 31, 921 (1992).

Yang, M. C. and E. L. Cussler, "Designing Hollow-Fiber Contactors," AIChE J., 32, 1910 (1986).

Yeon, S. H., B. Sea, Y. I. Park, K. S. Lee, and K. H. Lee, “Adsorption of Carbon Dioxide Characterized by Using the Absorbent Composed of Piperazine and Triethanolamine," Sep. Sci. Technol., 39, 3281 (2004).

Yeon, S. H., B. Sea, Y. I. Park, and K. H. Lee, "Determination of Mass Transfer Rates in PVDF and PTFE Hollow Fiber Membranes for $\mathrm{CO}_{2}$ Absorptions," Sep. Sci. Technol., 38, 271 (2003). 